To cite this article: Er S, Topçu R, Tikici D, Özden S, Tez M. Fournier gangreninde mortaliteyi öngörmede skorlama sistemlerinin değerlendirilmesi. Turk J Clin Lab 2019; 10: 230-234.

- Orjinal Makale

\title{
Fournier gangreninde mortaliteyi öngörmede skorlama sistemlerinin değerlendirilmesi
}

\section{Evaluation of scoring systems in predicting mortality in Fournier gangrene}

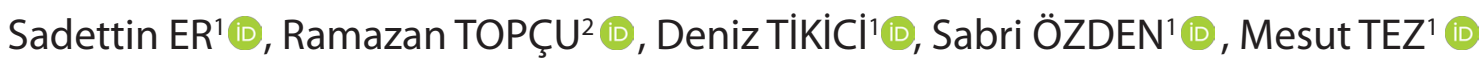

1Sağlık Bilimleri Üniversitesi, Ankara NumuneEğitim ve Araştırma Hastanesi, Genel Cerrahi Kliniği, Ankara/TÜRKIYE ${ }^{2}$ Hitit Üniversitesi, Erol Elçok Eğitim ve Araştırma Hastanesi, Genel Cerrahi Kliniği, Çorum/TÜRKIYE

Öz

Amaç: Fournier gangreni hastalarında şiddet ve mortaliteyi öngörmede skorlama sistemlerini değerlendirmeyi amaçladık. Gereç ve Yöntemler: Çalışmaya dahil edilen 76 hastanın demografik, klinik ve laboratuvar verileri elektronik ortamda retrospektif olarak incelendi. Çalışmada her hasta için demografik özellikleri, klinik ve laboratuvar parametrelerini içeren FGSI, UFGSI ve NFS skorları hesaplandı. Skorların ROC analizi yapıldı. Analizimiz sonucunda $\mathrm{p}<0,05$ olanlar istatistiksel olarak anlamlı kabul edildi.

Bulgular: Çalışmaya dahil edilen 76 hastanın 65(\%85,5)'i taburcu edilirken, $11(\% 14,5)^{\prime}$ inde mortalite gelişti. Tüm hastalar, Grup-1:Taburcu edilen hastalar ve Grup-2: Mortalite gelişenler olarak iki gruba ayrıldı. ROC((receiver operating characteristic) analizinde; FGSI, UFGSI ve NFS skorları için AUC (Area Under The Curve=Eğrinin Altında Kalan Alan) sırasıyla 0,890 (\%95 Cl: 0.785-0.994, $\mathrm{p}=0.000$ ), 0,895 (\%95 Cl: 0.810-0.981, $\mathrm{p}=0.000$ ) ve 0,867 (\%95 Cl: 0.733-1, $\mathrm{p}=0.000$ ) olarak bulundu.

Sonuç: İdeal bir skorlama sistemi; bu hastalığı daha iyi anlamak, beklenmedik mortalite durumlarında hataları tanımlayabilmek ve sağkalıma katkıda bulunabilmeyi amaçlamalıdır. NFS'nin basit, kolay değerlendirilen parametreler içeren bir skorlama sistemi olduğunu ve klinik pratikte mortaliteyi değerlendirmede oldukça faydalı olabileceğini düşünüyoruz.

Anahtar kelimeler: Fournier gangreni; mortalite; skorlama

Sorumlu Yazar*: Sadettin ER, Sağlık Bilimleri Üniversitesi, Ankara Numune Eğitim ve Araştırma Hastanesi, Genel Cerrahi Kliniği, Ankara/TÜRKiYE E-posta: ersadettin74@gmail.com 


\begin{abstract}
Aim: We aimed to evaluate the scoring systems in predicting severity and mortality in patients with Fournier gangrene. Material and Methods: Demographic, clinical and laboratory data of 76 patients included in the study were retrospectively analyzed. Demographic characteristics, clinical and laboratory parameters including FGSI, UFGSI and NFS scores were calculated for each patient. ROC analysis of the scores was performed. $\mathrm{P}<0.05$ was considered statistically significant.

Results: Of the 76 patients included in the study, 65 (85.5\%) were discharged and 11 (14.5\%) had mortality. All patients were divided into two groups: Group-1: Discharged patients and Group-2: Mortality. In ROC (receiver operating characteristic) analysis, AUC (Area Under The Curve) for FGSI, UFGSI and NFS scores was 0.890 ( $95 \%$ Cl: $0.785-0.994, p=0.000$ ), 0.895 (95\% Cl: $0.810-$, respectively). $0.981(p=0.000)$ and $0.867(95 \% \mathrm{Cl}: 0.733-1, p=0.000)$.

Conclusion: An ideal scoring system; to better understand this disease, to identify errors in unexpected situations and mortality should aim to be able to contribute to survival. We believe that NFS is a scoring system with simple, easy-toevaluate parameters and may be very useful in assessing mortality in clinical practice.
\end{abstract}

Key words: Fournier gangrene; mortality; scores

\section{Giriş}

Fournier gangreni (FG), fasiyal planlar arasından karın duvarına kadar uzayabilen genital, perianal ve perineal bölgenin nadir, hızla ilerleyen ve fulminant bir nekrotizan fasiit durumudur [1]. Enfeksiyonun nedeninin, vakaların \% 95'inde esasen anorektal, genitoüriner ve deriden kaynaklandığı bildirilmiştir [2]. Erken tanı ya da tedavi edilmezse sepsise ve çoklu organ yetmezliğine kadar ilerleyebilir [3]. Literatürde mortalite oranlarının \%1330.8 arasında değişkenlik gösterdiği ifade edilmiştir [4]. Diyabet ve immünsüpresyon gibi predispozan faktörler, vasküler ve polimikrobiyal enfeksiyona duyarlıığı arttırarak FG oluşumunu kolaylaştırmaktadır. Teşhis genellikle klinik bulgulara ve fizik muayeneye dayanır. Prevalansının, Afrika'da, immünosupresif tedavi alan veya insan immün yetmezlik virüsü (HIV) geçiren hasta sayısının artmasıyla artış gösterdiği bildirilmiştir [5].

Son yirmi yılda birçok çalışma, farklı skorlama sistemlerinin FG hastalarının mortalitesini öngörüdeki önemini vurgulamıştır. Günümüzde FG şiddet ındeksi (FGSI), Uludağ FG şiddet ındeksi (UFGSI) ve NUMUNE Fournier Skoru (NFS) hastalığın derecesini değerlendirmek ve ölüm oranlarını tahmin etmek için kullanılmaktadır [6]. Erken tanı, hastanın agresif resusitasyonu, geniş spektrumlu antibiyotik verilmesi, agresif radikal cerrahi ve debridmanlar başarılı tedavinin anahtarıdır. Bu çalışmada, FG hastalarında şiddet ve mortaliteyi öngörmede skorlama sistemlerini değerlendirmeyi amaçladık.

\section{Gereç ve Yöntemler}

\section{Hastaların verileri}

Fournier gangreni tanısı ile 2014-2018 yılları arasında Sağlık Bilimleri Üniversitesi Ankara Numune Eğitim ve Araştırma Hastanesi ile Hitit Üniversitesi Tıp Fakültesi Genel Cerrahi Kliniklerine başvuran 76 hastanın demografik, klinik ve laboratuvar verileri elektronik ortamda retrospektif olarak incelenerek elde edildi. Çalışmada her hasta için demografik özellikleri, klinik ve laboratuvar parametrelerini içeren FGSI, UFGSI ve NFS skorları hesaplandı. Bu skorların parametreleri: FGSı için başvuru sırasındaki vücut sıcaklığı, kalp atış hızı, solunum hızı, serum sodyum, serum potasyum, serum kreatinin ve serum bikarbonat konsantrasyonları, hematokrit ve lökosit sayılarını içermekte, normal değerlerden bir sapma 0 ila 4 arasında derecelendirilmektedir. FGSI'ye yaş ve vücuda yayılma skorları eklenmiş ve UFGSI olarak ifade edilmiştir. Bunlara ilaveten NFS skoruda yaş>60, kan üre nitrojen seviyesi $>40$ mg/ dl, kırmızı hücre dağılım genişliği >\%14.95, albümin düzeyi <20 $\mathrm{mg} / \mathrm{dl}$ ve sepsis varlığı gibi parametreleri içermektedir.

FG tanısı hastanın öyküsüne, klinik semptomlara, lokal hassasiyet, ödem, eritem, şişlik, krepitasyon, perianal, perineal ve buralardan kaynaklanan enfeksiyonun genital bölgeye yayılımı veya bu bölgedeki nekroz gibi bulgulara dayanıyordu. Sadece soliter perianal, periüretral, skrotal apseli ve belirgin bir yumuşak dokuya uzanım veya nekroz olmayan hastalar çalışmaya dahil edilmedi. 
NFS parametrelerinden sepsis varlığı sistemik inflamatuar yanıt sendromuna ait kriterlerden elde edildi. Çalışma planı lokal etik kurulu tarafından incelenerek onaylanmıştır. Hastalardan imzalı aydınlanmış onam formları alınmıştır.

\section{İstatiksel analiz}

Tüm istatistiksel analizler SPSS 17.0 sürümü kullanılarak yapıldı. Non-parametrik devamlı değişkenler için sonuçlar medyan (IQR=interquartile range) olarak verildi. Kategorik değişkenler yüzde (\%) olarak ifade edildi. ROC (Receiver Operating Characteristic) analizi kullanılarak skorların eğrinin altında kalan alanlar \%95 Cl (Confidence Interval=güven aralığı) ile verildi. Analizimiz sonucunda $\mathrm{p}<0.05$ olanlar istatistiksel olarak anlamlı kabul edildi.

\section{Bulgular}

Çalışmaya dahil edilen 76 hastanın 25 (\%32.9)'i kadın ve 51 (\%67.1)'i erkekti. Bu hastaların 65 (\%85.5)'i taburcu edilirken, 11 (\%14.5)'inde mortalite gelişti. Tüm hastalar, Grup-1:Taburcu edilen hastalar ve Grup-2: Mortalite gelişenler olarak iki gruba ayrıldı.

Hastaların yaşı Grup-1 ve Grup-2'de m=medyan (IQR=interquartile range) sırasıyla, 55 (30-63) ve 62 (51-80) idi. Grup-1'deki hastaların yatış süresi, FGSI, UFGSI ve NFS skorlarının m(IQR)'e göre sırasıyla; 16 (4-29), 3 (0-6), 5 (1-8) ve 1 (1-2) olarak bulundu. Benzer şekilde Grup-2'deki hastaların yatış süresi, FGSI, UFGSI ve NFS skorlarının m(IQR)'e göre sırasıyla; 11 (2-32), 10 (3-11), 12 (6-15) ve 4 (1-5) idi (Tablo-1).

\begin{tabular}{|c|c|c|}
\hline \multicolumn{3}{|c|}{$\begin{array}{l}\text { Tablo-1: Grup-1 ve 2'deki hastaların demografik verileri, } \\
\text { yatış süresi ve fournier şiddet skorlarının arasındaki ilişkisi }\end{array}$} \\
\hline Değişkenler & $\begin{array}{c}\text { Grup-1 } \\
\mathrm{n}=65\end{array}$ & $\begin{array}{c}\text { Grup-2 } \\
\mathrm{n}=11\end{array}$ \\
\hline Yaş & $55(30-63)$ & $62(51-80)$ \\
\hline \multicolumn{3}{|l|}{ Cinsiyet } \\
\hline Erkek(\%) & $46(70,8)$ & $5(45,5)$ \\
\hline Kadın(\%) & $19(29,2)$ & $6(54,5)$ \\
\hline Yatış süresi & $16(4-29)$ & $11(2-32)$ \\
\hline FGSI & $3(0-6)$ & $10(3-11)$ \\
\hline UFGSI & $5(1-8)$ & $12(6-15)$ \\
\hline NFS & $1(1-2)$ & $4(1-5)$ \\
\hline \multicolumn{3}{|c|}{ m(IQR): medyan(interquartile range) } \\
\hline
\end{tabular}

ROC (receiver operating characteristic) analizinde; FGSI, UFGSI ve NFS skorları için AUC (Area Under The Curve=Eğrinin Altında Kalan Alan) sırasıyla 0.890 (\%95 Cl: 0.785-0.994, p=0.000), 0,895 (\%95 Cl: 0.810-0.981, p=0.000) ve 0,867 (\%95 Cl:0.733-1, p=0.000) olarak bulundu. Bu analizde, NFS skoru mortalite tahmininde diğer skorlarla benzer etki gücüne sahipti (Tablo-2 ve Şekil-1).

\begin{tabular}{|c|c|c|c|}
\hline \multicolumn{4}{|c|}{$\begin{array}{l}\text { Tablo-2: FGSI, UFGSI, ve NFS için ROC analizinde eğrinin } \\
\text { altında kalan alan için sayısal veriler }\end{array}$} \\
\hline Değişkenler & EAA & $\% 95 \mathrm{Cl}$ & p değeri \\
\hline FGSI & 0,890 & $0,785-0,994$ & $0,000^{*}$ \\
\hline UFGSI & 0,895 & $0,810-0,981$ & $0,000^{*}$ \\
\hline NFS & 0,867 & 0,733-1 & $0,000^{*}$ \\
\hline \multicolumn{4}{|c|}{$\begin{array}{l}\text { FGSI: Fournier Gangreni Şiddet Indeksi } \\
\text { UFGSI : Uludağ Fournier Gangreni Şiddet Indeksi } \\
\text { NFS: NUMUNE Fournier Skoru } \\
\text { EAA: Eğrinin Altındaki Alan } \\
\text { Cl: Confidence Interval } \\
\text { *: Istatiksel anlamlı }\end{array}$} \\
\hline
\end{tabular}

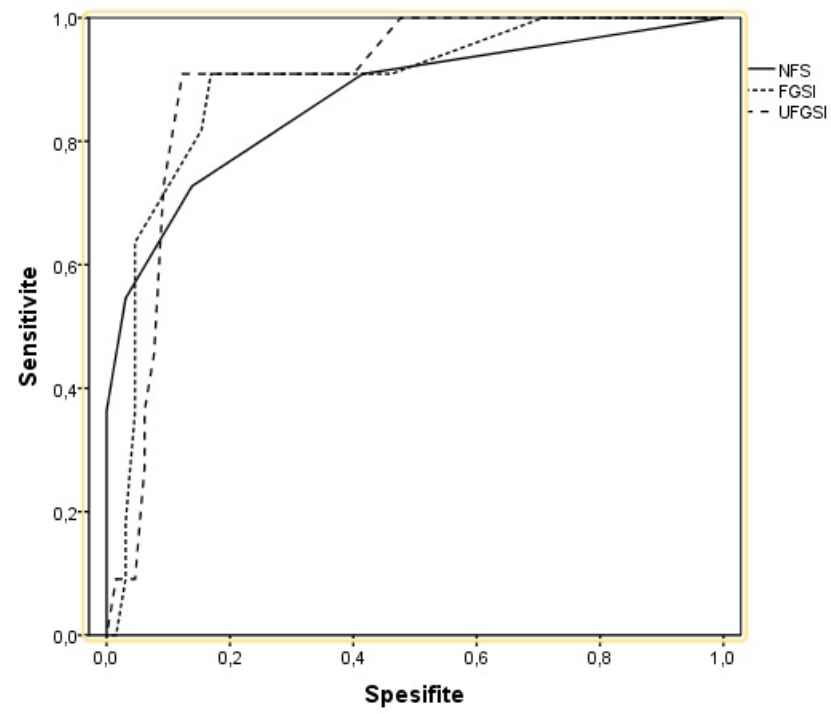

Şekil-1: FGSI, UFGSI VE NFS skorlarının ROC analizinde EAA

\section{Tartışma}

FG nadir görülen perine ya da genital organları tutan, bazen batın anterior veya lateral duvarına doğru hızla ilerleyen ve etkin medikal veya cerrahi tedavi başlanmadığında hayatı tehdit eden bir durumdur. Tedavi yaklaşımları, yoğun antibiyotik tedavileri ve yoğun bakım ünitelerindeki gelişmelere rağmen mortalite oranları halen \%10 - 40 arasında olduğu bildirilmektedir [4,7]. Mevcut çalışmada da genel mortalite oranı \%14.5 olarak bulunmuştur. Literatürde mortalite ile ilişkili olabilecek hastaya ait faktörler arasında yaş, ek hastalıklar, semptomların süresi ve hastalığın yayılımı ile şiddeti ileri sürülmektedir [8]. Son yıllarda hayatta kalan hastaların yaşlarının daha küçük olduğunu gösteren çalışmaların sayısı giderek artmaktadır [9]. 
Yayınlanan birçok çalışmada mortalite gelişen hastaların yaş ortalaması 40.9-61.7 arasında bildirilmektedir [10]. Çalışmamızda mortalite gelişen hastalarda medyan yaş 62 (5180) idi. Bu çalışmada, sağ kalan hastalar mortalite gelişenlere göre daha gençti. Bu sonuç literatürdeki birçok çalışma ile korelasyon göstermektedir [11,12].

Mathew D. Sorensen ve ark.[10]'nın yapmış olduğu çalışmada mortalite oranı hastanede yatış süresi uzadıkça daha yüksek olarak bulunmuş, fakat çalışmamızda mortalite gelişenlerde sağ kalanlara göre medyan yatış süresi daha kısa olarak bulundu.

Hastalığın yayılımı veya şiddeti FG hastalarında mortalite için bağımsız ve en önemli risk faktörü olduğu bildirilmiştir [13]. FGSI, UFGSI ve NFS gibi skorlar, FG hastalarında hastalığın şiddetini ve prognozunu öngörmek üzere geliştirilen objektif skorlama sistemleridir. FGSI Laor ve ark.[12], UFGSI Yılmazlar ve ark.[11] ve NFS skoru Erdoğan ve ark.[6] tarafından hastalığın şiddeti ve mortalitesini öngörmek amacıyla tanımlanmıştır. FGSI, FG hastalarında mortalite oranını \%75 ve sağ kalım oranını \%78 tahmin edebilir [12]. UFGSI, FGSI'ye ilaveten yaş ve hastalık yaygınlığı kriterlerini de içermektedir. Bunlara göre yeni tanımlanan NFS skoru yaş>60, kan üre nitrojen seviyesi $>40 \mathrm{mg} / \mathrm{dl}$, kırmızı hücre dağılım genişliği $>\% 14.95$, albümin düzeyi $<20 \mathrm{mg} / \mathrm{dl}$ ve sepsis varlığı anlamlı ve bağımsız mortalite belirleyicileriydi. Özellikle NFS skoru>3 olanlarda mortalite oranının \%50 olduğu bildirilmiştir [6]. Farklı bir çalışmada UFGSI $\geq 9$ olduğunda mortalitenin 13 kat arttığı ifade edilmiştir [14]. Literatürde FGSI skoru yüksek olan hastalarda mortalite oranının daha yüksek olduğu bildirilmekle birlikte[15], bu skorla mortalite arasında herhangi bir ilişkinin saptanmadığını bildiren yayınlar da bulunmaktadır [16].

Çalışmamızda ROC analizinde FGSI, UFGSI ve NFS skorları için eğrinin altında kalan alan benzer bulunmuştur $(p=0.000)$. Yine bu çalışmada, çalışmaya dahil edilen skorlama modellerinin tamamında mortalite gelişen hastaların medyan skorları sağkalanlara göre daha yüksek bulunmuştur. Fakat, mortaliteyi öngörmede NFS skorunun içerdiği parametrelerin diğer skorlara göre daha az sayıda olması, basit ve daha uygulanabilir olması önemli avantajlarındandır. Bu durum özellikle birinci ve ikinci basamak tedavi merkezlerinde mevcut parametrelerle hastanın hızla değerlendirilip bir üst merkeze yönlendirilmesini kolaylaştırabilir.

Çalışmamızı sınırlandıran ana faktörlerin, retrospektif ve benzer çalışmalar da olduğu gibi hasta sayısının düşük olması söylenebilir.
Sonuç olarak literatürde FG şiddeti ve mortalitesini öngören birkaç skorlama sistemi mevcuttur. FG, ideal mortalite tahmin modeli olmayan, düşük insidans ve yüksek mortalite oranına sahip bir hastalıktır. İdeal bir skorlama sistemi; bu hastalığı daha iyi anlamak, beklenmedik mortalite durumlarında hataları tanımlayabilmek ve sağkalıma katkıda bulunabilmeyi amaçlamalıdır. Ancak, bu skorların daha geniş serilerle doğrulanması gerekmektedir. Çalışmamızda skorların mortaliteyi öngörü gücü yüksek olmakla birlikte, yakın dönemde tanımlanan NFS'nin basit, kolay değerlendirilen parametreler içeren bir skorlama sistemi olduğunu ve klinik pratikte mortaliteyi değerlendirmede oldukça faydalı olabileceğini düşünüyoruz.

\section{Çıkar çatışması / finansal destek beyanı}

Bu yazıdaki hiçbir yazarın herhangi bir çıkar çatışması yoktur. Yazının herhangi bir finansal desteği yoktur

\section{Kaynaklar}

1. Corman J, Moody J, Aronson W. Fournier's gangrene in a modern surgical setting: improved survival with aggressive management. BJU international 1999; 84: 85-88.

2. Paty R, Smith A. Gangrene and Fournier's gangrene. The Urologic clinics of North America 1992; 19: 149-62.

3. Luther Ward M, Eisenson D, Fils J-L. Fournier's gangrene of the penis in a 12-year-old patient secondary to phimosis. Rhode Island Medical Journal 2016; 99: 45.

4. Benjelloun EB, Souiki T, Yakla N et al. Fournier's gangrene: our experience with 50 patients and analysis of factors affecting mortality. World Journal of Emergency Surgery 2013; 8: 13.

5. Morua AG, Lopez J, Garcia J, Montelongo RM, Guerra L. Fournier's gangrene: our experience in 5 years, bibliographic review and assessment of the Fournier's gangrene severity index. Arch Esp Urol 2009; 62: 532-40.

6. Erdoğan A, Aydoğan I, Şenol K, Üçkan E, ErsözŞ, Tez M. Simple scoring system for prediction of mortality in Fournier's gangrene. European Journal of Trauma and Emergency Surgery 2016; 42: 513-18.

7. Eke N. Fournier's gangrene: A review of 1726 cases. British Journal of Surgery. 2000; 87: 718-28.

8. Küçükdurmaz F. Fournier gangreninde mortaliteyi etkileyen faktörlerin değerlendirilmesi: 38 hastalık deneyimimiz. Yeni Üroloji Dergisi 2016; 12: 29-34. 
9. Tarchouli M, Bounaim A, Essarghini M et al. Analysis of prognostic factors affecting mortality in Fournier's gangrene: A study of 72 cases. Canadian Urological Association Journal 2015; 9: 800.

10. Sorensen MD, Krieger JN, Rivara FP, Klein MB, Wessells H. Fournier's gangrene: management and mortality predictors in a population based study. The Journal of urology 2009; 182: 2742-47.

11. Yilmazlar T, Ozturk E, Ozguc H, Ercan I, Vuruskan H, Oktay B. Fournier's gangrene: an analysis of 80 patients and a nove scoring system. Techniques in coloproctology 2010; 14: 217-23.

12. Laor E, Palmer LS, Tolia BM, Reid RE, Winter HI. Outcome prediction in patients with Fournier's gangrene. The Journal of urology 1995; 154: 89-92.

13. Dahm P, Roland FH, Vaslef SN et al. Outcome analysis in patients with primary necrotizing fasciitis of the male genitalia. Urology 2000; 56: 31-35.
14. Yılmazlar T, Işık Ö, Öztürk E, Özer A, Gülcü B, Ercan İ. Fournier's gangrene: review of 120 patients and predictors of mortality. Ulus Travma Acil Cerrahi Derg. 2014; 20: 333-37.

15. Erol B, Tuncel A, Hanci V et al. Fournier's gangrene: overview of prognostic factors and definition of new prognostic parameter. Urology 2010; 75: 1193-98.

16. Janane A, Hajji F, Ismail $T$ et al. Hyperbaric oxygen therapy adjunctive to surgical debridement in management of Fournier's gangrene: Usefulness of a severity index score in predicting disease gravity and patient survival. Actas Urológicas Españolas (English Edition) 2011; 35: 332-38. 